\title{
FREE-RIDER PROBLEM IN CLASSROOM GAMES - IMPACT OF GENDER AND INTERGROUP CONDITIONS
}

\author{
Soňa Kukučkováp, Pavel Žiaran ${ }^{1}$ \\ ${ }^{1}$ Department of Finance, Faculty of Business and Economics, Mendel University in Brno, Zemědělská 1, 61300 \\ Brno, Czech Republic
}

To cite this article: KUKUČKOVÁ SOŇA, ŽIARAN PAVEL. 2018. Free-rider Problem in Classroom Games-Impact of Gender and Intergroup Conditions. Acta Universitatis Agriculturae et Silviculturae Mendelianae Brunensis, 66(6): 1517-1525.

To link to this article: https://doi.org/10.11118/actaun201866061517

\begin{abstract}
Behavioural experiments in the field of provision of public goods (including free rider problem) help to uncover the underlying processes and forces determining the nature of economy in the public sector. The objective of this paper is to determine the impact of gender and intergroup conditions on the extent of cooperation in standard linear public goods game using the voluntary contribution mechanism. Design of the teaching experiment is based on the methodology of Špalek (2011) with some modification. There were 80 undergraduate students of business participating in the classroom game, age range 20-22 years. Students were divided into three independent groups by 26 to 27 participants. Each group was playing independently, and individual strategies were recorded. We used the nonparametric tests (Mann-Whitney U test and Kruskal-Wallis Test) to analyse the differences between the gender and groups. Findings do not show statistically significant difference based on gender. On the other hand, the intergroup conditions determined by the social dynamics and discussion have significant influence on the distribution of goods. Results bring strong evidence on the importance of social and political factors influencing the pro-social behaviour in the society.
\end{abstract}

Keywords: public goods game, voluntary contribution mechanism, free-rider problem, cooperation, gender

\section{INTRODUCTION}

Linear public goods games are often used for classroom experiments to present the voluntary contribution mechanism (VCM) and the free-riding problem. In a public goods game participants choose how much of an initial endowment they want to contribute to a group account. The money on the group account from all players is multiplied by a certain multiplier and is divided among all, regardless if they contributed or not. The group account represents pure public goods with their definition features: non-excludability in their benefits and non-rivalry in consumption.
Players have their own strategies between two extremes: to contribute their entire endowment to the provision of public goods and to maximize the group welfare (the Pareto efficient result for all participants), or not to contribute and free-ride because it could be seen as more optimal privately (the Nash equilibrium strategy). The free-rider problem is based on the concept of hommo economicus - rational agents trying to maximize their own utility do not contribute to the public goods because they hope that others would. In Stiglitz (1988) individuals have no incentives to pay for public services voluntarily and that is why they must be forced to pay through taxation. 
First experiments testing the free-rider problem did not confirm that the free-riding was a predominant behavioural strategy (Bohm 1972; Dawes et al., 1977; Ames and Marwell; 1981). Later, experiments were more focused on finding the factors which enable to increase the average contribution rate (e.g. The marginal per capita return, gender, group size, communication, repetition, positive framing, experienced participants, subject's beliefs regarding others' participants' behaviour).

Our paper aims to determine the impact of the chosen factors on the extent of cooperation in standard linear public goods game using the voluntary contribution mechanism. We have conducted the classroom experiment what enables us to have participants with similar backgrounds for decision-making. We focused on the factors: gender and intergroup differences in individual strategies during the whole session. The intergroup differences could relate to the communication possibilities and character features of group members. In this area existing empirical evidence still does not provide unambiguous results.

The paper is structured as follows: first part of the paper summaries the results of current empirical studies concerning the analysed factors and their impact on the extent of cooperation. Then, the classroom game design, research questions and methods are presented. The conducted teaching experiment demonstrates different impact of the gender and intergroup differences on the pro-social behaviour in the society. In the part discussion the results of our classroom game are evaluated and compared with other similar economic and teaching experiments.

\section{Literature Review}

Empirical research focused on the gender impact on the contribution rate in linear public games and prisoner 's dilemma experiment is not uniform. In contrary, it could not be determined whether men or women contributed more in general.

Zelmer (2001) used meta-analysis technique to assess the impact of various factors on the rate of contribution to public goods in linear public goods experiments (27 studies were included). Gender was identified as not significant, because there was little variability among the studies. However, communication between subjects improved cooperation.

Tab. I summarizes results of empirical studies concerning the impact of gender on the extent of cooperation.

Rapoport and Chammah (1965) found that men chose cooperative strategies significantly more than women (in prisoners' dilemma). Similarly, Leuthold's teaching experiments (1992) confirmed that women free-rode more than men, but the difference was not relevant. Brown-Kruse and Hummels (1993) wanted to test their interpretation of the theory of Gilligan (1982) suggesting that women contribute more to the group welfare, but the results were reversed. Similarly, in Holt and Laury (1997) women contribute less to the public good than men. But authors are aware that gender effects might interact with the social context in which decisions are made.

Cadsby and Mynes (1998) replicated the experimental results of Brown-Kruse and Hummels (1993) with a different random recruitment mechanism and found no significant gender differences. Ortmann and Tichy (1995) studied a prisoner's dilemma game based on the similar principles than the linear public goods games and at the beginning of the game, women were significantly more cooperative. By the end, there was no significant difference between males and females. Spalek (2011) did not find significant gender differences during the whole experiment but outlined some differences when conditions changed (after group discussion and the change of cost of contribution).

McCorkle and Watts (1996) used the same version as Leuthold (1992) for Ukrainian economics teachers without any modification of the main game principles. Their results were dissimilar - women contributed more than men. Nowell and Tinkler (1994) found some evidence that all-female groups are more cooperative than either all-male or mixed gender groups.

Beliefs and the framing effect are also indicated as important factors causing gender differences in behaviour connected with cooperativeness. Aguiar et al. (2009) analysed beliefs about altruisms and generosity in a dictator game. While women believe that women are more generous, men consider that women are as generous as men. In

I: Impact of gender on the extent of cooperation in empirical studies

\begin{tabular}{ccc}
\hline Men contribute more & No significant differences & Women contribute more \\
\hline Rapoport and Chammah (1965) & Ledyard (1995) & Gilligan (1982) \\
Leuthold (1987, 1992) & Cadsby and Maynes (1998) & Nowell and Tinkler (1994) \\
Brown-Kruse and Hummels (1993) & Ortmann and Tichy (1999) & McCorkle and Watts (1996) \\
\hline Holt and Laury (1997) & Zelmer (2003) & Špalek (2011) conditionally \\
& Špalek (2011) in general & \\
\hline
\end{tabular}

Source: Own elaboration 
contrary, Vyrastekova et al. (2015) did the experiment to identify gender beliefs in a public goods game and their impact on cooperation. Men expected the groups to be more cooperative when more women were in the group. No direct effect in the contribution rate in different groups was found when there was a control for beliefs. These results under control could explain dissimilar gender behavior in past experiments. In Bruttel and Stolley (2018) the effect of two different frames on decisions in a dictator game for males and females was tested (emphasizing either decision power or responsibility). Women were more generous when using a text that emphasizes their decision power and men reacted positively to a text that stresses their responsibility for the receiver.

Our classroom game tests also the impact of discussion/communication about the group strategy as a part of the intergroup conditions analysis. In most experiments the possibility to communicate increases the rate of contribution to the group account. In Zemler's meta-analysis (2001) the communication is the factor with a positive and significant effect on the average level of contribution to the public good. In Isaac and Walker (1988) communication has improved group optimality significantly-with no communication the tendency to zero contribution was shown. The paper findings differ from the results of the most empirical studies in this area. In our teaching experiment there was different impact of the group discussion on the rate of contribution to the common account depending on the discussion content and on the existence of the "successful or unsuccessful" leader in the group.

\section{MATERIALS AND METHODS}

\section{Design of the teaching experiment}

The teaching experiment in the form of classroom game was conducted in winter 2017 during seminars in Public finance at the Mendel University in Brno. There were 80 undergraduate students of business participating in the classroom game, age range 20-22 years. They had some background knowledge in economics (starting the 7th term). Students were randomly divided into three independent groups (26 and 27 participants), $75 \%$ of them were women.

Students had neutral instruction about the game (no information about the free riding problem or about the other possible strategies); length of the game was known. The session had 9 rounds and participants had 2 points to use for each round. They could keep them on their personal account or invest them to the common/group account (choosing 0, 1 or 2 points on the website to invest).

The points on the group account from all players were multiplied by $10 \mathrm{CZK}$ and this amount was earnings for all players, regardless if they contributed or not. The points on the personal account were multiplied by 40 CZK for rounds $1-3$ and 7-9 and by 20 CZK for rounds 4-6. After the 6th round the group discussion was possible to propose the strategy for last three rounds. The goal of the session for a student was to maximize the points on their individual account. During the session there was no intervention from the side of a teacher. Participants recorded their individual strategy on paper sheets (including points on the individual account, sum on the common account and the whole remuneration). Anonymity for recording was required and no communication was allowed except of the group discussion after 6th round.

There were some differences in the design of classroom game compared to Špalek (2011). First, the voting was via smartphones not via cards. Second, the use of Google forms for our teaching experiment enabled to show the results after each round including the amount of the points for the group of men and for the group of women. Therefore, the participants had information not only about the total amount on the group account but also about the choice of the group of women and the group of men. This change could have impact on their strategies and beliefs. Third, the gender ratio was different in our groups than in Špalek (2011). In our groups the gender ratio was in average $75 \%$ in favour of women, in the groups of Špalek (2011) there were only slightly more women than men (52\% of women).

\section{Methods}

As a general objective we search for understanding of internal processes in the group decision-making on the free-riding phenomenon, that is the outcome of group dynamics and inner group processes.

The objective of this paper is to determine the impact of gender and intergroup conditions on the extent of cooperation in standard linear public goods game using the voluntary contribution mechanism. In line with theoretical research and current findings in other empirical studies we formulate research questions as follows:

1. Is there a difference between males and females in total points on the personal account during the whole session (how many points did they keep)?

2. Is there a difference between various groups in total points on the personal account during the whole session (depending on the intergroup conditions)?

We analysed points on individual account for each person during all rounds focused on the gender and intergroup conditions. We used the nonparametric test (Mann-Whitney U test and Kruskal-Wallis Test) to analyse the differences between the gender and groups. Every person was assigned to the defined strategy types and the share of the different types inside the groups A, B, C and the groups of women and men was determined.

We defined 5 types of individual strategies according the total points on the personal account 
II: Individual strategy types used in analysis

\begin{tabular}{lc}
\hline & Points on personal account \\
\hline Pure Giver & 0 \\
Partial Giver & Less than 9 \\
Mixed Strategy & 9 \\
Partial Keeper & More than 9 \\
Pure Keeper & 18 \\
\hline
\end{tabular}

Source: authors

during the whole session. Maximum of points that could be kept on individual account is 18 (9 rounds per 2 points) - the person did not contribute to the group account and could be described as the "Pure Keeper". This strategy is the pure free-riding strategy that was in line with the "hommo economicus" concept. Another extreme is the "Pure Giver" - this strategy means that the person invested all points on the group account and there are no points on his/her personal account. To contribute all points to the group account is the strategy that maximizes the group welfare. The "Mixed strategy" is in the middle of the spectrum of all individual strategies and it represents the person who contributed 1 point in average for each round.

The most used strategies are both "Partial" strategies - "Partial Keeper" with the tendency to be more individual and "Partial Giver" with the inclination to act in accordance with the group needs. Shares of those two types of strategies on all strategies for the group of women are compared with the group of men; the same comparison is done for groups A, B, C.

Then, comparison of the average rate of the contribution to the common account was carried out for the group of men and women; and for each group of participants.

\section{RESULTS}

Following chapter depicts results in the subsections containing gender and intergroup differences. First part focuses on gender differences, second part deals with intergroup processes.

We used the Mann-Whitney U test to analyze the differences between genders analyzing the total score during the whole session represented by total points on the personal account. Fig. 1 depicts the boxplot for the males and females, where we can identify slight difference.

However, Mann-Whitney test (Tab. III) shows that there is no statistical difference between genders in the total score in the game $(\mathrm{p}<0.05)$.

Additionally, we compared individual strategies in groups A, B, C between the group of women and the group of men during the whole session. The results are shown in the Fig. 2. The differences in partial strategies were not significant. The share of partial givers differed by $1.77 \mathrm{pp}$ and the share of partial keepers in the group of men were only $5 \mathrm{pp}$ higher than in the group of women. Even, when there was the absence of pure givers in the group of men, the share of pure givers was only $5 \%$ in the group of women. Therefore, no significant difference was found.

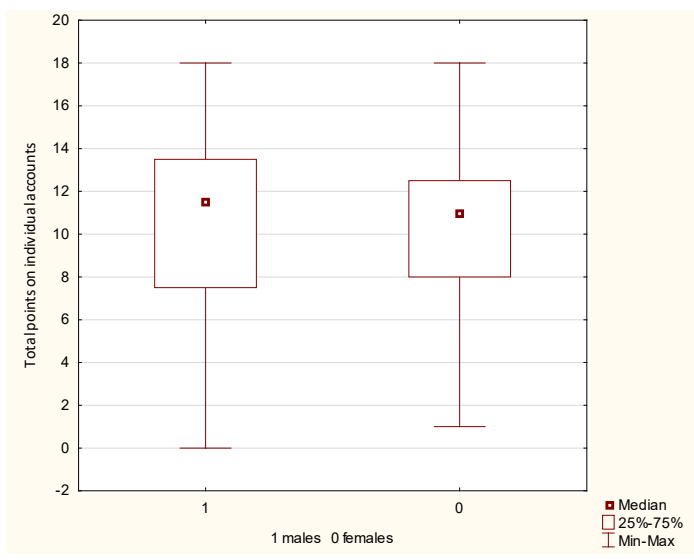

1: Box plot, total points on individual accounts, gender differences Source: authors

III: Mann-Whitney test, differences between males and females, total points on individual accounts in the game, $N=80$

\begin{tabular}{lcccc}
\hline & $\mathbf{U}$ & $\mathbf{Z}$ & p-value & Z (adjusted) \\
\hline Total score & 583,00 & 0,18 & 0,85 & 0,18 \\
\hline
\end{tabular}

Source: authors 
Finally, the comparison of the rate of the contribution to the common account was carried out for the group of men and women (Fig. 3). For rounds $1-3$ the rate of the contribution to the common account is higher for the group of men; for rounds 4-9 the rate of the contribution to the common account is higher for the group of women, but the differences in both cases are not relevant. The average rate of the contribution to the common account for all rounds was $41.4 \%$ for men, $41.6 \%$ for women and $41.5 \%$ for all participants.

In the next part we analyze the differences between the groups which were playing the game separately (intergroup conditions). Fig. 4 depicts
Strategies in all groups for men

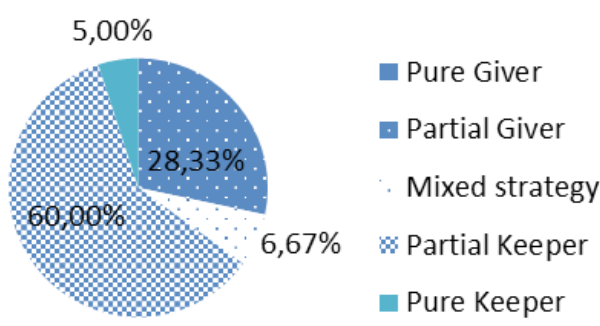

Strategies in all groups for women

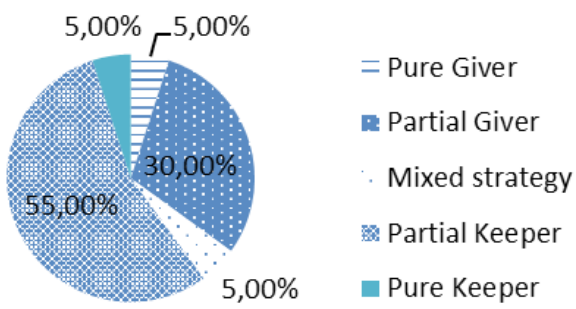

2: Gender differences in individual strategies types for all groups Source: authors

Rate of the contribution to the common account for men and women

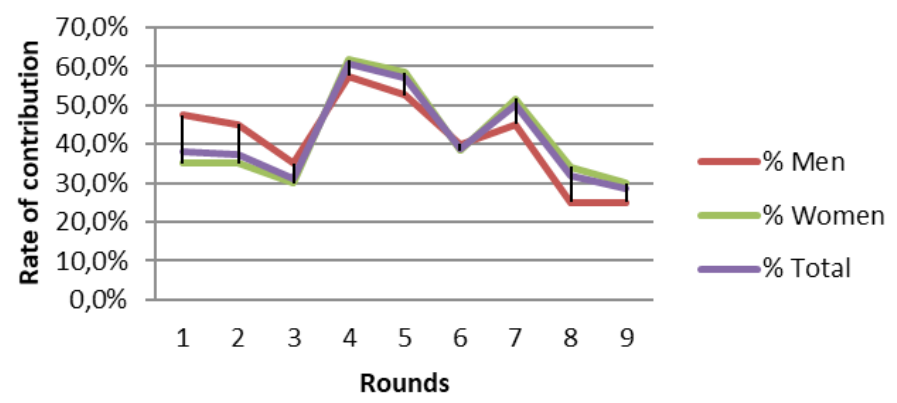

3: Rate of the contribution to the common account for men and women (9 rounds of the game) Source: authors

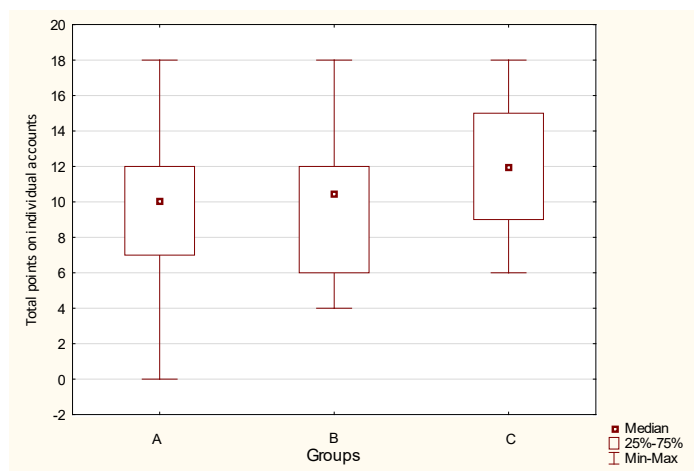

4: Box plot, total points on individual accounts, gender difference Source: authors

IV: Kruskal-Wallis Test, differences among the groups, total points on individual account, $N=80, * p<0.1$

\begin{tabular}{lccc}
\hline & $\mathbf{A}(\mathbf{R}: \mathbf{3 4 , 9 2 6 )}$ & $\mathbf{B}(\mathbf{R}: 36,385)$ & $\mathbf{C}(\mathbf{R}: \mathbf{5 0 , 0 3 7 )}$ \\
\hline $\mathbf{A}$ & & 1,000 & $0,051^{*}$ \\
$\mathbf{B}$ & 1,000 & & $0,098^{*}$ \\
$\mathbf{C}$ & $0,051^{*}$ & $0,098^{*}$ & \\
\hline
\end{tabular}

Source: authors 
boxplot of total scores in the game (points on individual account), analyzing the three separate scores of the groups. Group A and group B achieved relatively similar scores. On the other hand, group $C$ achieved significantly higher score-there were more points kept on the personal/individual accounts.

Kruskal-Wallis Test (tab. 4) shows that there is a significant difference in the total score between the group A and group B versus the group C.

These results were supported by the analysis of individual strategies during the whole game. We abstracted from the both "pure" strategies and focused on the shares of partial givers, partial keepers and mixed strategies. Mixed strategy was not represented in the group B.

The highest difference between the share of partial givers and the share of partial keepers was $48.2 \mathrm{pp}$ in the group $\mathrm{C}$ and the smallest difference was $14.9 \mathrm{pp}$ in the group A. High share of partial keepers in the group $\mathrm{C}$ could be the result of significant decrease of the contribution rate to the common account after group discussion.

When we compare the rate of the contribution to the common account for each group of participants, dissimilar development for the group $A$ and the group C compared to the group B could be identified in rounds after discussion (Fig. 5). In the $7^{\text {th }}$ round, the rate of the contribution to the common account for the group B was distinctively higher than in the groups $\mathrm{A}$ and $\mathrm{C}$ and there was a decline of the rate of the contribution to the common account for the group $\mathrm{A}$ and $\mathrm{C}$. The rate of the contribution to the common account for the group A was higher than in both other groups for rounds 1-6.

The average rate of the contribution to the common account for all rounds was $47.5 \%$ for the group A, $42.9 \%$ for the group B and $34.2 \%$ for the group C. We can see that the average rate of the contribution to the common account is 7.3 pp lower for the group C than the average rate for all participants. Decline of the rate of contribution to the common account for the group A in last three rounds was compensated by higher rate of contribution for rounds 1-6 compared to group $\mathrm{B}$ and $\mathrm{C}$.

\section{DISCUSSION}

The results of the paper could be compared with Špalek (2011). We have partly modified his design of the classroom game therefore, some differences in our results could be expected. First, in our groups of participants the gender ratio was in average $75 \%$ in favour of women, in the groups of Špalek (2011) there were only slightly more women than men ( $52 \%$ of women). Second, after each round we showed not only the results for the whole group but also the amount of the points for the group of men and for the group of women. Figures 6 and 7 depict the rates of the contribution to the common account (rate of cooperation) in our classroom game and in the teaching experiment of Špalek (2011) during the whole session.

Fig. 6 represents the rates of cooperation related to gender diversity and fig. 7 displays average rate of the contribution for all groups and genders. The main differences were demonstrated after $6^{\text {th }}$ round when discussion was possible in both teaching experiments. Špalek (2011) found that after discussion the contribution rate to the common account increased. This statement was in line with our results, but for the the $7^{\text {th }}$ round the growth was lower for all groups (women and men) than in Špalek (2011).

The average rate of contribution to the common account compared to Špalek (2011) was higher in our

V: Shares of individual strategies types in groups A, B, C in \%

\begin{tabular}{lccc}
\hline & Group A & Group B & Group C \\
\hline Partial Giver & 33.3 & 34.6 & 18.5 \\
Mixed strategy & 11.1 & 0.0 & 7.4 \\
Partial Keeper & 48.2 & 61.5 & 66.7 \\
\hline
\end{tabular}

Source: authors

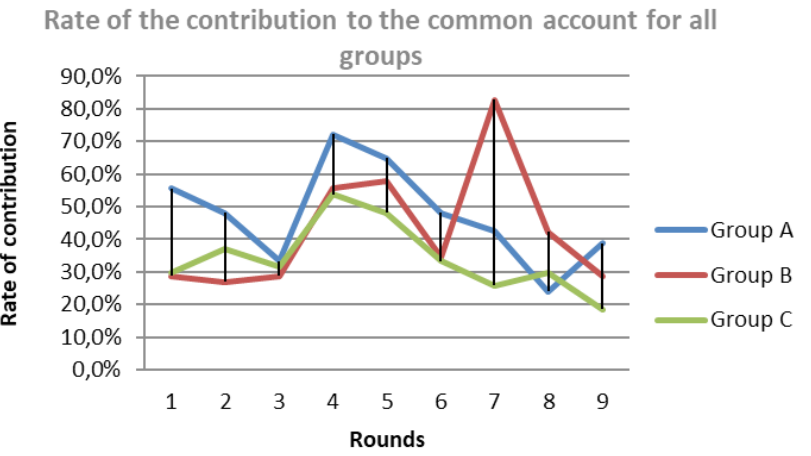

5: Rate of the contribution to the common account for all groups (9 rounds of the game) Source: authors 
Rate of the contribution to the common account for men and women

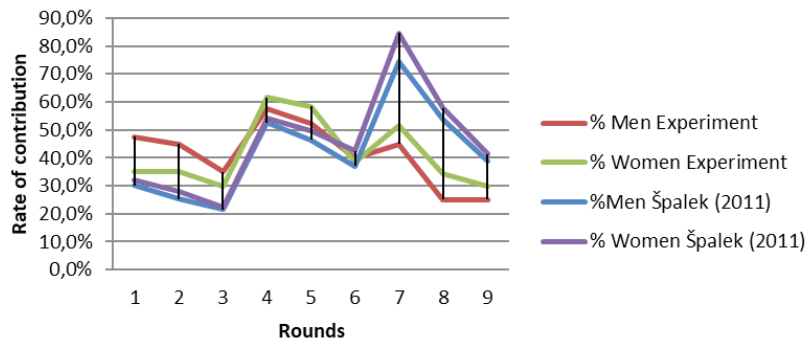

6: Rate of the contribution to the common account for men and women (9 rounds of the game) Source: Authors, Špalek (2011)

Average rate of contribution to the common account in our teaching experiment and in Špalek (2011)

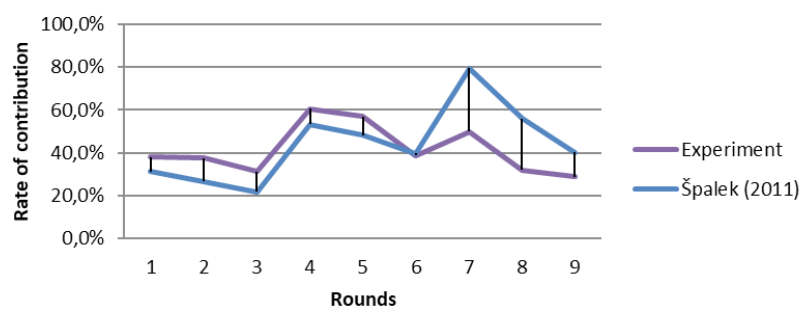

7: Average rate of the contribution to the common account (9 rounds of the game) Source: authors, Špalek (2011)

classroom game for rounds 1-6 (before discussion); however, they did not differ significantly. But there was opposite difference for rounds 7-9 when the cooperation was higher in the teaching experiment of Špalek (2011). The evaluation failed to show that in the groups with more women (average share was $75 \%$ ) the rate of contribution to the common account was not higher for all rounds than in Špalek (2011) with 52\% of women. It is not possible to conclude that the groups with more women contributed more to the common account. In contrary, when we compare the average rate of contribution to the common account in both teaching experiments, the rate of Špalek (2011) is by $2.6 \mathrm{pp}$ higher than in our experiment (41.5\%). Details of this comparison for each round could be seen in Fig. 7. Lower contribution rate in our classroom game after communication could be explained by intergroup differences which will be discussed in the next part.
In the group $\mathrm{C}$ there was considerable drop in cooperation after discussion what had impact on the total points on the individual account and therefore the significant difference between groups occurred. We could observe during the discussion that one student tried to persuade other participants to invest all to the group account as the only right strategy but with his interpretation he frustrated the others. In the group A decline of the rate of contribution to the common account could be explained by an impressive speech of one student - he explained his strategy to keep all points on personal account as the best solution for each individual participant.

The result was decline in contribution rate to the common account for last three rounds. We could see that communication and the person of leader (successful or unsuccessful) had notable impact on the extent of cooperation.

\section{CONCLUSION}

The objective of this paper was to determine the impact of gender and intergroup conditions on the extent of cooperation in standard linear public goods game using the voluntary contribution mechanism.

Mann-Whitney test and performed analysis of individual strategy types showed that there was no significant statistical difference between genders in total points on the personal account during the whole session. The absence of pure altruists/givers in the group of men was not sufficient to show predominance of women in cooperation behaviour. The average rate of the contribution to the common account for all rounds was only 0.1 pp lower for men and 0.1 pp higher for women than the average rate for all participants.

Analysis of intergroup conditions showed different results for the group C compared to other groups the group $\mathrm{C}$ achieved significantly higher score (points kept on the personal account). This difference 
was verified by Kruskal-Wallis and the analysis of individual strategy types. The reason for more points kept on the personal/individual accounts in group $\mathrm{C}$ could be the development of contribution rate to the common account after the group discussion as it had been already mentioned before.

The average rate of the contribution to the common account for all rounds was 7.3 pp lower for the group $C$ than average and $6 \mathrm{pp}$ higher for the group A. The rate of cooperation for the group B was slightly above average (1.4 pp).

We plan modify our future research in following directions. First, it could be reasonable to conduct the same analysis for six rounds first (without discussion) and then for last three rounds separately and compare the results with Špalek (2011) to avoid distortion because of the communication and to focus on gender differences. Second, more detailed analysis of each member of the group could be added to determine the differences in the group via psychological tests (focused on cooperativeness, competitiveness and leadership). Finally, we plan to obtain more data from further teaching experiments with modified experimental design (e.g. testing of gender beliefs and framing effects).

In most empirical studies regarding the linear public goods game there is positive effect of the communication on the rate of contribution to the public goods. But our findings show that if there was an unsuccessful leader or the successful leader promoting the free-riding strategy the impact could be opposite. Results bring strong evidence on the importance of social and political factors influencing the pro-social behaviour in the society.

\section{REFERENCES}

AGUIAR, F., BRAÑAS-GARZA, P., COBO-REYES, R., JIMENEZ, N. and MILLER, L. M. 2009. Are women expected to be more generous? Experimental Economics, 12(1): 93-98.

AMES E. E. and MARWELL, G. 1981. Economist free ride, does anyone else? Experiments in the provision of public goods. Journal of Public Economics, 15(3):295-310.

ANDREONI, J. 1988. Why free ride? Strategies and learning in public goods experiments. Journal of Public Economics, 37(3): 291-304.

BEIL, R. and NELSON, R. G. 1994. When Self-interest is Self-Defeating: The Public Goods Experiment as a Teaching Tool. Journal of Agricultural $\sigma$ Applied Economics, 26(2): 580-590.

BERNÁ, Z. and ŠPALEK, J. 2011. Threshold Effectiveness in Contributing to the Public Goods: Experiments Involving Czech Students. Prague Economic Papers, 3: 250-267.

BERNÁ, Z. 2014. Voluntary cooperation in experiment with public goods. Doctoral thesis. Brno: Masaryk University. BOHM, P. 1972. Estimating demand for public goods: An experiment. European Economic Review, 3(2): 111-130.

BROWN-KRUSE, J. and HUMMELS, D. 1992. Gender effects in laboratory public goods contribution: Do individuals put their money where their mouth is? Journal of Economic Behavior and Organization, 22(3): 255-267.

BRUTTEL, L. and STOLLEY, F. 2018. Gender Differences in the Response to Decision Power and Responsibility-Framing Effects in a Dictator Game. Games, 9(2): 28.

CADSBY, C. B. and MAYNES, E. 1998. Gender and free riding in a threshold public goods game: Experimental evidence. Journal of Economic Behavior $\sigma$ Organization, 34(4): 603-620.

DAWES, R. M. 1980. Social dilemmas. Annual review of psychology, 31(1): 169-193.

DAWES, R. M., MCTAVISH, J. and SHAKLEE, H. 1977. Behavior, communication, and assumptions about other people's behavior in a commons dilemma situation. Journal of personality and social psychology, 35(1): $1-11$.

FRANK, R., GILOVICH, T. and REGAN, D. 1993. Does studying economics inhibit cooperation? Journal of Economic Perspectives, 7(2): 159-171.

GILLIGAN, C. 1982. In a different voice, psychological theory and women's development. Cambridge, MA: Harvard University Press.

HOLT, A. CH. and LAURY, S. K. 1997. Voluntary Provision of a Public Good. Journal of Economic Perspectives, 11(4): 209-215.

ISAAC, R. M. and WALKER, J. M. 1988. Communication and Free-Riding Behavior: The Voluntary Contribution Mechanism. Economic Inquiry, 26(4): 585-608.

LEDYARD, J. 1995. Public Goods. A Survey of Experimental Research. In: KAGEL, J. H. and ROTH, A. E. (Eds.). Handbook of Experimental Economics. Princeton: Princeton University Press, pp. 111-194.

LEUTHOLD, J. H. 1992. A Free Rider Experiment for Large Class. Faculty working paper No. 92-0157, digitized at Urbana Campaign 2011.University of Illinois. Available at: https://www.ideals.illinois.edu/bitstream/ handle/2142/29376/freeriderexperim92157leut.pdf?sequence=2. [Accessed: 2018, April 13].

LEUTHOLD, J. H. 1987. A public goods experiment for the classroom. Journal of Economic Education, 18(1): 58-65. MC CORKLE, S. and WATTS, M. 1996. Free Riding Indexes for Ukrainian Economics Teachers. Journal of Economic Education, 18: 233-237. 
NOWELL, C. and TINKLER, S. 1994. The influence of gender on the provision of a public good. Journal of Economic Behavior and Organization, 25: 25-36.

ORTMANN, A. and TICHY, L. 1999. Gender differences in the laboratory: evidence from prisoner's dilemma games. Journal of Economic Behavior F Organization, 39: 327-339.

RAPOPORT, A. and CHAMMAH, A. 1965. Prisoners dilemma: A study in conflict and cooperation. Ann Arbor, MI: University of Michigan Press.

STIGLITZ, J. E. 1988. Economics for the Public Sector. $3^{\text {rd }}$ Edition. New York: Norton.

ŠPALEK, J. 2011. Veřejné statky. Teorie a experiment. $1^{\text {st }}$ Edition. Prague: C. H. Beck.

ŠPALEK, J. and BERNÁ, Z. 2011. Threshold Effectiveness in Contributing to the Public Goods: Experiments Involving Czech Students. Prague Economic Papers, 3: 250-267.

VYRASTEKOVA, J., SENT, E. M. and VAN STAVEREN, I. 2015. Gender Beliefs and Cooperation in a Public Goods Game. Economics Bulletin, 35(2): 1148-1153.

WATTS, M. and GUEST, R. 2010. Experimental Economics and Economic Education. Editorial Issue 9. 2. International Review of Economics Education, 9(2): 6-9.

ZELMER, J. 2001. Linear Public Goods Experiments: A Meta-Analysis. Report no.361. The Research institute for Quantitative Studies in Economics and Population. Available at: http://socserv.mcmaster.ca/qsep/p/ qsep361.pdf [Accessed 2018, August 17]. 